\title{
GAMBARAN TRUST PADA DEWASA AWAL YANG MENGALAMI PERCERAIAN ORANGTUA DAN SEDANG BERPACARAN (STUDI KASUS DI JAKARTA)
}

\author{
Ira $^{1}$ dan Denrich Suryadi ${ }^{2}$ \\ ${ }^{1}$ Fakultas Psikologi, Universitas Tarumangara Jakarta \\ Email: iralianaa@gmail.com \\ ${ }^{2}$ Fakultas Psikologi, Universitas Tarumangara Jakarta \\ Email: denrichs@fpsi.untar.ac.id
}

\begin{abstract}
ABSTRAK
Perceraian orang tua adalah kejadian yang berdampak pada hidup seseorang. Sementara itu tugas perkembangan individu pada masa dewasa awal adalah intimacy versus isolation. Persahabatan yang kaya mengandung komponen yang bermanfaat keintiman. Salah satu komponen tersebut adalah trust atau rasa percaya. Trust merupakan sesuatu yang tak ternilai dalam hubungan dekat manapun karena trust membuat rasa saling bergantung semakin enak, membuat kita bersedia untuk berinvestasi di dalam hubungan tersebut, dan membuat kita berusaha untuk melindungi dan merawat hubungan tersebut. Terdapat lima karakteristik dari trust yang disebutnya lima A, yaitu attention, acceptance, appreciation, affection, allowing. Penelitian ini menggunakan teknik wawancara semi terstruktur kepada 4 individu yang berusia 19-30 yang mengalami perceraian orang tua dan sedang menjalin hubungan dengan lawan jenis. Penelitian ini bertujuan untuk mengetahui tentang gambaran pemenuhan karakteristik dan faktor yang mempengaruhi pembentukan trust pada individu dewasa awal yang mengalami perceraian orang tua, karena di masa tersebut individu sedang mencari hubungan dengan orang lain ataupun lawan jenis. Studi ini berlangsung selama 4 bulan dari Maret sampai Juni 2015. Hasil dari penelitian ini adalah 3 dari 4 subyek memenuhi kelima karakteristik trust. Selain dipengaruhi oleh latar belakang keluarga, rasa trust subyek juga dipengaruhi oleh riwayat hubungan dengan lawan jenisnya.
\end{abstract}

Keywords: trust, perceraian orangtua, hubungan pacaran, dewasa awal

\section{PENDAHULUAN}

\section{Latar Belakang}

Ketika pernikahan tidak berjalan sesuai yang diinginkan, banyak pasangan memutuskan untuk berpisah dari pasangannya alias bercerai. Herrington dan Kelly (dikutip dalam Conklin, 2008) menggolongkan alasan bercerai ke dalam empat kategori, kategori pertama dan yang terluas adalah kesulitan dalam hubungan, termasuk perselingkuhan, susah untuk menjalin keintiman, berbeda pengharapan, masalah dengan pekerjaan di rumah, dan masalah lain yang dihadapi selama pernikahan. Kategori kedua adalah masalah pemasukan atau gaji, berkelimpahan atau kekurangan uang dapat menjadi masalah dalam pernikahan. Kategori ketiga adalah masalah seksual, ketika suami ingin seks yang banyak supaya mendapat kepuasan pernikahan sementara istri ingin kualitas seks yang lebih baik. Kategori keempat adalah kekerasan, baik secara fisik, psikologis, seksual atau emosional.

Perceraian sendiri berdampak pada kedua pasangan dan juga anak-anak mereka. Menurut penelitian yang dilakukan oleh Dermawan dan Sutaryo (2011), perceraian membuat anak sulit mengungkapkan perasaannya apabila berhubungan dengan masalah pribadinya. Hal ini disebabkan karena subyek dalam penelitian tidak mendapat pengasuhan yang kompeten dari ibunya, sehingga anak terbiasa menghadapi masalahnya sendiri. Wallerstrein (dikutip dalam Ekos, The, \& Hastuti, 2010) juga mengungkapkan bahwa anak-anak dari keluarga yang orang tuanya bercerai harus lebih menyesuaikan diri terhadap masalah dibandingkan dengan anak-anak dengan orang tua yang tidak bercerai.

Ketika masa remaja, anak sedikit merasa bersalah atas perceraian orangtuanya namun lebih merasa kebencian (Berns, 2010). Mereka pun masih terbeban dengan ingatan menyakitkan mengenai perceraian orangtuanya 10 tahun kemudian (Wallerstein et al., dikutip dalam Berns, 2010). Santrock (2005) menyatakan bahwa akibat langsung dari perceraian bagi anak adalah distress emosional (internalizing disorders) seperti kecemasan, depresi dan yang kedua masalah perilaku (externalizing disorders) seperti acting out, kenakalan remaja. Anak remaja dengan orang tua bercerai juga kurang 
bertanggung jawab secara sosial, kurang kompeten dalam hubungan mesra, rendahnya self-esteem, menjadi aktif secara seksual di usia muda.

Dampak perceraian orang tua pun terasa sampai masa dewasa. Menurut Amato (2014), individu yang merasakan perceraian orangtua ketika tumbuh dewasa dilaporkan lebih memiliki masalah pada pernikahannya sendiri dan mereka lebih cenderung merasa pernikahannya akan berakhir juga. Christensen dan Brooks (dalam Fergusson, McLeod, \& Horwood, 2013) juga menyatakan bahwa perceraian atau perpisahan orangtua dapat menjadi pengalaman kehidupan yang mempengaruhi perilaku berhubungan individu di masa depannya.

Sementara ketika anak tumbuh dewasa khususnya dewasa awal, individu akan melalui fase sosioemosional intimacy versus isolation. Jika di masa ini individu tidak bisa membuat komitmen pribadi yang dalam kepada orang lain, individu beresiko menjadi terisolasi, walaupun terkadang mengisolasi diri itu dibutuhkan untuk merefleksi diri sendiri. Resolusi dari fase ini adalah love atau cinta dimana pasangan saling mengabdi dan setia untuk membagi hidupnya (Erikson dikutip dalam Papalia, et. al., 2009). Menurut Miller, Perlman dan Brehm (2007), perbedaan antara persahabatan dan romantisme adalah persahabatan kurang bergairah dibandingkan dengan hubungan asmara. Tetapi persahabatan yang kaya mengandung komponen yang bermanfaat keintiman. Komponen tersebut adalah respect, responsiveness, capitalization, social support, dan trust.

Trust merupakan sesuatu yang tak ternilai dalam hubungan dekat manapun karena trust membuat rasa saling bergantung semakin enak, membuat kita bersedia untuk berinvestasi di dalam hubungan tersebut, dan membuat kita berusaha untuk melindungi dan merawat hubungan tersebut (Wieselquist et al., dalam Miller, Perlman, \& Brehm, 2007). Trust membuat orang nyaman di dalam hubungan mereka, dan bagi yang kurang trust terhadap pasangannya cenderung menutup diri, curiga, dan kurang puas (Rempel et. al., dikutip dalam Miller, et al, 2007). Menurut Robbins dan Judge (2012). Trust bisa terbentuk karena 3 hal, yaitu integrity, benevolence, ability. Integritas (integrity) dapat diartikan sebagai jujur dan dapat dipercaya juga konsisten antara perkataan dan tindakan Benevolence artinya orang yang kita percaya mempunyai minat yang tulus terhadap kita, seperti perhatian dan suportif. Ability atau kemampuan mencangkup skill, dan pengetahuan interpersonal dan teknikal seseorang.

Menurut Richo (2011), ada lima karakteristik trust yang disebutnya five A's yaitu attention (perhatian), acceptance (penerimaan), appreciation (apresiasi), affection (afeksi/kasih sayang), allowing (mengizinkan). Kualitas dari allowing penting untuk pertumbuhan dan membuat ruang bagi individu untuk merasakan hidup yang penuh, tanpa ada pembatasan atas emosi, self-expression, atau pilihan individu. Allowing terkait dengan tiga area berikut, pertama, individu bebas menunjukan perasaannya tanpa diinterupsi, dihukum maupun dipermalukan. Kedua, individu memiliki hak penuh serta dorongan untuk hidup berdasarkan keinginan terdalam, nilai-nilai, dan harapan individu. Ketiga, langkah individu dimuluskan oleh pengasuh yang melindungi dan "melepas" individu untuk membuat pilihan sendiri.

Penelitian yang dilakukan oleh Ramadhini dan Hendriani (2015) menyatakan bahwa faktor yang membentuk trust pada perempuan dewasa awal yang menjalani pernikahan jarak jauh adalah pengalaman pada masa pacaran, intensitas pertemuan, dukungan keluarga, sifat dan karakter suami, dan religiusitas. Sementara itu kehilangan trust juga mempunyai efek korosif pada hubungan yang dekat (Miller \& Rempel dikutip dalam Miller, Perlman, \& Brehm, 2007). Menurut Zimmerman dan Thayer (2003), dunia anak yang sudah dewasa yang orangtuanya bercerai berdasar pada pengalaman hilangnya rasa percaya atau trust. Pada titik tertentu, mereka memiliki ekspektasi bahwa orangtua dan keluarganya akan bertahan sebagai suatu kesatuan telah hancur. Mereka tahu bahwa janji yang telah 
dibuat akhirnya dilanggar. Sementara orangtua mengajarkan agar mempercayai tiap hubungan yang ada, selalu setia dan berdedikasi.

Sementara menurut Wallerstein, et al. (dikutip dalam Piotrkowski, 2008), dampak jangka panjang perceraian orangtua tidak terlihat sampai masa remaja atau dewasa awal ketika cinta datang. Dari penelitian selama 25 tahun pada 93 orang dewasa berumur 28 sampai 43 tahun dari keluarga yang bercerai dan kelompok pembanding menemukan bahwa orang dewasa dengan keluarga bercerai lebih cemas dibanding kelompok pembandingnya mengenai hubungan percintaan, kurang percaya, lebih mungkin memilih pasangan yang disfungsi, lebih mungkin bercerai jika mereka menikah sebelum umur 25 tahun, dan lebih mungkin tidak menikah. Pada penelitian ini, penulis ingin mengetahui tentang gambaran pemenuhan karakteristik dan faktor yang mempengaruhi pembentukan trust pada individu dewasa awal yang mengalami perceraian orang tua, karena di masa tersebut individu sedang mencari hubungan dengan orang lain ataupun lawan jenis.

\section{Rumusan Masalah}

Bagaimana gambaran trust pada dewasa awal yang sedang berpacaran dan mengalami perceraian orang tua khususnya di Jakarta?

\section{Tujuan Penelitian}

Mengetahui gambaran trust pada dewasa awal yang sedang berpacaran dan mengalami perceraian orang tua di Jakarta.

\section{METODE PENELITIAN}

\section{Partisipan Penelitan}

Partisipan penelitian ini adalah pria/wanita dewasa awal, yaitu pria atau wanita yang berumur 19-30 tahun. Orang tua subyek bercerai pada saat subyek dalam tahap usia perkembangan 6-12 tahun atau middle childhood, subyek juga sedang menjalin hubungan (pacaran).

\section{Desain Penelitian}

Penelitian ini merupakan penelitian dengan metode kualitatif. Penelitian kualitatif adalah penelitian yang berusaha menjelaskan makna dari suatu masalah. Penelitian menggunakan teknik wawancara dengan jenis wawancara yang di gunakan adalah semi-stuktur yaitu dengan panduan wawancara juga probing dari jawaban subyek. Selain itu, dilakukan juga observasi, baik observasi perilaku non-verbal subyek, juga observasi suasana wawancara.

\section{Instrumen Penelitian}

Peralatan yang digunakan dalam penelitian ini adalah panduan wawancara, alat rekam, baterai cadangan, alat tulis seperti bolpen untuk mencatat jawaban subyek dan untuk subyek mengisi informed consent.

\section{Prosedur Penelitian}

Penulis sebelumnya telah mencari teori terkait tema penelitian, Setelah itu penulis membuat panduan wawancara dan kemudian peneliti mencari subyek yang sesuai dengan kriteria penelitian ini. Penulis mendapat keempat subyek dari kenalan penulis. Penulis membangun rapport terlebih dahulu melalui 
BlackBerry Messenger kemudian baru membuat janji wawancara pengambilan data. Pengambilan data dimulai dari maret 2015 sampai Mei 2015.

\section{HASIL DAN PEMBAHASAN}

Penelitian ini mengkaji gambaran trust pada dewasa awal yang sedang berpacaran dan mengalami perceraian orangtua. Dari hasil wawancara berdasarkan bentuk trust, dapat disimpulkan bahwa LL memenuhi tiga dari empat bentuk trust, yaitu interpersonal trust, reality trust, dan trust in higher power. LL tidak memenuhi self-trust yaitu LL merasa tidak percaya dengan dirinya sendiri. Sementara pada interpersonal trust, LL percaya kepada ibunya dan LL kurang percaya terhadap pacarnya. CO memenuhi tiga dari empat bentuk trust, yaitu interpersonal trust, reality trust, dan trust in higher power. $\mathrm{CO}$ tidak memenuhi self-trust yaitu $\mathrm{CO}$ merasa tidak percaya dengan dirinya sendiri. Sementara pada interpersonal trust, CO percaya kepada pacarnya karena CO tidak akrab dengan orangtuanya. JL memenuhi keempat bentuk trust, JL percaya terhadap dirinya sendiri yaitu self-trust, JL juga percaya pada pacarnya serta orangtua dan orangtua tirinya, terutama ibu kandungnya. dan YC memenuhi keempat bentuk trust, YC percaya pada dirinya sendiri, dan orang yang YC percaya adalah pacarnya, karena YC tidak akrab dengan orangtuanya.

Kemudian berdasarkan pemenuhan karakteristik trust dapat disimpulkan bahwa LL memenuhi tiga dari lima karakteristik trust. Karakteristik trust yang tidak dimiliki oleh LL adalah attention dan allowing. LL tidak terbiasa memberikan perhatian pada pacarnya, begitu pula pacarnya yang menurut LL tidak begitu peduli. LL juga tidak sepenuhnya terbuka dengan pacarnya. Tiga subyek lainya yaitu CO, JL dan YC memenuhi kelima karakteristik trust. CO, JL dan YC dapat memberikan perhatian pada pacarnya (attention), dapat menerima pacarnya (acceptance), dapat mengapresiasi pacarnya (appreciation), dapat menyayangi pacarnya (affection), dan dapat mengizinkan pacarnya masuk kehidup subyek (allowing).

\section{KESIMPULAN, SARAN, DAN DISKUSI \\ Kesimpulan}

Berdasarkan hasil wawancara dapat disimpulkan bahwa 2 dari 4 subyek hanya memenuhi 3 bentuk trust. Kedua subyek tidak merasa memiliki self trust atau rasa percaya kepada diri sendiri. Sementara berdasarkan karakteristik trust, 1 dari 4 subyek yang hanya memenuhi 3 dari 5 karakterisktik trust. Karakteristik yang tidak terpenuhi adalah allowing dan attention.

\section{Diskusi}

Penelitian skripsi sebelumnya adalah membahas trust pada pasangan yang berpacaran jarak jauh. Hasil dari penelitian tersebut adalah dari tiga pasangan yang menjalani hubungan jarak jauh, dua di antaranya memenuhi karakteristik trust. Setelah itu penulis tertarik untuk meneliti trust pada anak korban perceraian. Penelitian ini meneliti individu yang mengalami perceraian orang tua ketika sedang dalam masa perkembangan middle childhood, dengan rentang usia 6-12 tahun (Papalia, et. al., 2009) yang sekarang sedang dalam masa perkembangan dewasa muda yaitu rentang usia 19-30 tahun (Erikson dikutip dalam Feist \& Feist, 2009) yang saat ini sedang melalui tugas tahap perkembangan intimacy vs isolation, maka subyek yang dilibatkan adalah subyek yang sedang menjalin hubungan dengan lawan jenis dan mengalami perceraian orangtua. Penulis mendapatkan keempat subyek yang berusia 20-22 tahun, yang sedang berpacaran antara satu sampai empat tahun, orangtua keempat subyek bercerai ketika berusia enam sampai sebelas tahun.

Menurut subyek pertama, LL, dirinya merasa stres karena diperebutkan oleh kedua orangtuanya disebabkan pengalaman LL dari kecil yang berpindah-pindah dari rumah ibu atau ayahnya. Bahkan ketika subyek sudah lulus LL diminta tinggal dengan ayahnya. Menurut LL, yang lebih memengaruhi hubungan dirinya dengan lawan jenis adalah mantan pacarnya yang posesif. LL tidak lagi mau mencari 
pasangan yang mengekang dirinya. Sekarang LL berpacaran dengan wanita yang memberi kebebasan seperti ibunya memberi kebebasan. Namun walaupun ia senang dengan hubungan sekarang, LL merasa kekurangan dari hubungannya ialah ia tidak begitu tahu kondisi pacarnya.

LL dalam masalah akan mencari ibunya karena ibunya lebih enak diajak berdiskusi, sedangkan LL jarang meminta bantuan pacar, biasanya ia bercerita hanya masalah kecil. Hal ini mungkin tersambung dengan gaya berpacaran LL yang saling memberi kebebasan. Sampai LL bingung menjawab bagaimana caranya saling memberi perhatian dengan pacar, yang mana merupakan salah satu dari karakteristik trust. Menurutnya, perhatian hanya diberikan contohnya ketika pacarnya sakit. Pacar LL pun menurutnya kurang perhatian dan cuek. Menurut LL perhatian dalam sebuah hubungan itu penting, namun jangan sampai menjadi intrusive. LL mengaku dirinya trauma memiliki pacar yang posesif, akibat itu dirinya jarang meminta izin sebelum melakukan sesuatu dan juga masih memiliki rahasia yang disembunyikan dari pacarnya walaupun ia mengaku saling terbuka satu sama lain. LL pun mengaku terkadang dirinya merasa sangat sayang dengan pacarnya, namun terkadang dirinya memiliki rasa yang biasa saja dengan pacarnya. Menurut LL agar tidak terlalu mengebu-gebu rasa cintanya, namun ujungnya jenuh dan akhirnya putus. Hal ini sesuai dengan teori dari Zimmerman dan Thayer (2003), masalah pada dewasa awal yang orangtuanya bercerai, yaitu pengubah (changers), melekat pada pasangan (clingers), penyabotase (sabotagers), dan menjaga jarak (distancers). LL termasuk menjaga jarak (distancers), karena LL merasa tidak perlu terlalu mengebu-gebu cintanya.

Sedangkan bagi subyek kedua, CO, merasa tidak memiliki figur ayah karena perceraian orangtuanya. Setelah kejadian itu pun $\mathrm{CO}$ banyak dirawat oleh asisten rumah tangga dan neneknya sehingga $\mathrm{CO}$ merasa tidak begitu dekat dengan ibu dan adik lelakinya karena sang ibu sibuk bekerja mencari nafkah. Oleh sebab itu CO percaya dengan pacarnya, karena dalam masalah CO akan bercerita semua ke pacarnya sedang cerita ke ibunya tidak sedalam cerita dengan pacarnya. $\mathrm{CO}$ pun pernah dibohongi oleh mantan pertama karena waktu itu dirinya bertemu lewat game online. Semenjak kejadian dibohongi itu dan kenyataan bahwa orangtuanya bercerai karena ayah $\mathrm{CO}$ berselingkuh, $\mathrm{CO}$ tidak bisa percaya seratus persen ke orang lain.

CO mengaku walau ia percaya sekali dengan pacarnya, ia tetap curiga dan tidak bisa percaya seratus persen, dirinya pun sadar bahwa harus menghilangkan rasa curiga dengan pacarnya untuk menggapai pernikahan dan keluarga yang diidamkan. Hal ini sesuai dengan teori dari Zimmerman dan Thayer (2003), masalah pada dewasa awal yang orangtuanya bercerai, yaitu pengubah (changers), melekat pada pasangan (clingers), penyabotase (sabotagers), dan menjaga jarak (distancers). CO termasuk yang melekat pada pasangan (clingers), karena CO merasa posesif pada pacarnya, walaupun CO tidak percaya seratus persen kepada pacarnya.

Kemudian subyek ketiga, JL, orangtuanya bercerai ketika ia berusia kira-kira 8 tahun. Beberapa tahun kemudian kedua orangtuanya menikah lagi dan JL memiliki saudara tiri. LL juga tidak mengetahui penyebab perceraian orangtuanya. Namun JL tidak merasakan akibat dari perceraian orangtua, mungkin disebabkan adanya ayah dan ibu tiri yang menurut JL hubungan mereka baik-baik saja. JL juga tidak mengungkapkan akibat dari pengalaman pernah diselingkuhi mantan terhadap hubungannya sekarang ini. Mungkin saat itu JL masih kecil dan menganggap pacaran masih belum serius. JL cukup berbesar hati menerima pacarnya yang menurut JL kekanakan, hal tersebut merupakan karakteristik trust yaitu acceptance. Hal ini sesuai dengan teori dari Zimmerman dan Thayer (2003), masalah pada dewasa awal yang orangtuanya bercerai, yaitu pengubah (changers), melekat pada pasangan (clingers), penyabotase (sabotagers), dan menjaga jarak (distancers). Teori dari Zimmerman dan Thayer ini tidak berlaku pada JL.

Selanjutnya subyek keempat yaitu YC, semasa kecilnya pernah mengalami kekerasan fisik dan psikologis dari ibunya ketika ayah dan ibunya bertengkar, karena YC merupakan anak kesayangan ayahnya. YC juga pernah putus sekolah akibat perceraian orangtuanya. Namun YC bisa bangkit dari pengalaman buruk hidupnya berkat pembimbing rohani YC yang kurang lebih membantu YC melewati masa kelam hidupnya. Menurut YC sekarang dirinya mandiri walaupun tinggal dengan ibu 
dan ayah tirinya, walaupun sampai sekarang YC masih menerima kekerasan psikologis dari ibunya, walaupun ayah YC suka meminta uang kepadanya. YC mengaku dahulu ia mencari sebuah hubungan dengan lawan jenis agar dirinya mendapat kasih sayang yang tak ia dapat dari kedua orangtuanya. YC juga punya pengalaman dikhianati oleh mantan pacar dan temannya. Selama 4 tahun lebih YC dan pacarnya menjalin hubungan. Hal ini sesuai dengan teori dari Zimmerman dan Thayer (2003), masalah pada dewasa awal yang orangtuanya bercerai, yaitu pengubah (changers), melekat pada pasangan (clingers), penyabotase (sabotagers), dan menjaga jarak (distancers). YC termasuk melekat pada pasangan (clingers) walaupun YC tidak berhubungan intens dengan pacarnya. Namun YC hanya percaya terhadap pacarnya saja.

Tiga dari keempat subyek memenuhi kelima karakteristik trust, sedangkan LL hanya memenuhi tiga dari lima karakteristik trust. Dimana karakteristik trust yang tidak dimiliki LL adalah attention dan allowing. LL mengungkapkan bahwa ia bisa memberi perhatian saat pacarnya sakit, menurut LL juga pacarnya tidak perhatian. LL juga tidak sepenuhnya terbuka terhadap pacarnya, ia tak pernah meminta izin atau memberitahu aktivitasnya kepada pacarnya. Begitu pula dengan pacar LL.

Dari penelitian tentang pemenuhan karakteristik trust ini, didapat bahwa selain pengalaman masa kecil tentang orangtua, ternyata pengalaman subyek menjalin hubungan dengan lawan jenis juga mempengaruhi pembentukan trust. Dari keempat subyek, LL pernah merasakan memiliki hubungan dengan pacar yang posesif, sementara $\mathrm{CO}$ pernah dibohongi oleh mantan pacar, JL pernah diselingkuhi mantan pacarnya, YC pun pernah memiliki pengalaman pacarnya memutuskan hubungan mereka untuk menjalin hubungan dengan sahabat YC.

Dari penelitian yang penulis lakukan, ada beberapa kekurangan, yaitu secara eksternal penulis tidak bisa menentukan waktu pembuatan tugas akhir ini sehingga penulis hanya mempunyai kurang lebih empat bulan yaitu dari Maret sampai Juni untuk mengumpulkan data sampai akhirnya selesai. Kekurangan berikutnya adalah dari penulis yang mungkin tidak teliti dan sering menunda. Penulis juga kesulitan mencari teori tentang trust yang berhubungan dengan relationship. Kebanyakan penulis mendapat teori tentang company trust atau sejenisnya.

\section{Saran}

\section{Saran yang berkaitan dengan manfaat teoretis}

Selain meneliti dari kelompok umur dewasa awal yaitu 20 sampai 40 tahun, penelitian juga dapat diperluas pada kelompok umur remaja yaitu 13-18 tahun. Sehingga dapat diperoleh data yang lebih beragam dan memperlihatkan perbedaan pemenuhan Trust berdasarkan tahap perkembangan yang dilalui individu. Penelitian berikutnya juga disarankan untuk melibatkan jumlah subyek lebih lama untuk dapat melakukan generalisasi yang lebih dapat diandalkan.

\section{Saran yang berkaitan dengan manfaat praktis}

Saran bagi individu yang mengalami perceraian orangtua termasuk keempat subyek penelitian ini agar tabah, berupaya untuk memaklumi orangtua dan memastikan untuk menjadikan pembelajaran hidup ini menjadi sebuah pembelajaran penting ketika menikah dan berkeluarga nanti. Saran bagi keempat subyek untuk lebih selektif dan memberanikan diri dalam mencari pasangan atau lepas dari hubungan yang berpotensi buruk.

Saran bagi orangtua subyek agar juga memperhatikan kesejahteraan psikologis anak, yaitu dengan cara orangtua menghindari konflik di depan anak atau tidak melampiaskan amarah kepada anak. Saran bagi pasangan dari subyek, agar menerima pasangan apa adanya dan menghargai latar belakang subyek agar ada keterbukaan dari kedua belah pihak dalam menjalin hubungan. Penulis juga menyarankan untuk tidak menilai individu yang mengalami perceraian orang tua secara negatif.

\section{Ucapan Terima Kasih}

Proses penyusunan penelitian ini tidak terlepas dari bimbingan dan bantuan dari berbagai pihak, baik secara langsung maupun tidak langsung. Terima kasih kepada keempat subyek yang bersedia 
diwawancara untuk penelitian ini. Terima kasih juga kepada pihak Universitas yang telah mendukung terlaksananya penelitian ini.

\section{REFERENSI}

Pertimbangan sebelum bercerai. (2012). Diunduh dari http://female.kompas.com/read/2012/10/10/1809133/4.Hal.yang.Perlu.Dipertimbangkan.Sebelum. Bercerai.

Amato, P. R. (2014). The consequences of divorce for adults and children: An update. Društvena istraživanja: časopis za opća društvena pitanja, 23(1), 5-24.

Berns, R. M. (2010). Child, family, school, community: Socialization and support (8th ed.). US: Wadsworth.

Carr, A. (2013). Positive psychology: the science of happiness and human strength (2nd ed.). New York, NY: Routledge.

Dariyo, A. (2004). Psikologi perkembangan dewasa muda. Jakarta: Grasindo.

Conklin, S. E. (2008). Trust and intimacy in young adulthood: The impact of divorce. Massachusetts, MA: ProQuest LLC.

Dermawan, S., \& Sutaryo, L. P. P. (2011). Penyesuaian diri remaja yang tinggal dengan orang tua bercerai. Jurnal Penelitian Psikologi. 2(2), 201-219.

Ekos, S., The, M. \& Hastuti, R. (2010). Gambaran pengambilan keputusan menikah individu dewasa awal yang mengalami perceraian orang tua. Arkhe Jurnal Ilmiah Psikologi, 15(1), 66-80.

Fazriyati, W. (2012). 4 Masalah hubungan akibat perceraian orang tua. Diunduh dari http://female.kompas.com/read/2012/11/15/20210993/4.Masalah.Hubungan.Akibat.Perceraian.Or angtua

Feist, J.G. \& Feist, J. (2009). Theories of personality (7th ed.). New York, NY: McGraw-Hill.

Fergusson, D. M., McLeod, G. F., \& Horwood, L. J. (2014). Parental separation/divorce in childhood and partnership outcomes at age 30. Journal of Child Psychology and Psychiatry, 55(4), 352-360.

Herron, O. E. (2009). A qualitative study of trust and the superintendency. Ann Arbor, MI: ProQuest LLC.

Ihromi, T. O. (1999). Bunga rampai sosiologi keluarga. Jakarta: Yayasan Obor Indonesia.

King, L. A., (2011). The science of psychology: An appreciative view (2nd ed.). New York, NY: McGraw-Hill.

King, V. (2002). Parental divorce and interpersonal trust in adult offspring. Journal of Marriage and Family. 64(3). 642-656.

Lamanna, M. A, \& Riedmann, A. (2012). Marriages, families, and relationships (7th ed.). Belmont, CA: Wadsworth.

Miller, R. S., Perlman, D., \& Brehm, S. S. (2007). Intimate relationships (3rd ed.). New York, NY: McGraw-Hill.

Olson, D. H. \& DeFrain, J. (2000). Marriage and the family diversity and strengths (3rd ed.). California, CA: Mayfield

Papalia, D. E., Olds, S. W., \& Feldman, R. D., (2009). Human development (11st ed.). New York, NY: McGraw-Hill.

Piotrkowski, G. (2008). Children of divorce: confused love seekers. Westport, CT: Praeger Publishers.

Ramadhini, S., \& Hendriani, W. (2015). Gambaran trust pada wanita dewasa awal yang sedang menjalani long distance marriage. Jurnal Psikologi Klinis dan Kesehatan Mental, 4(1), 15.

Richo, D. (2010). Daring to trust: Opening ourselves to real love and intimacy. Boston, MA: Shambhala Publication Inc. 
Robbins, S. P., Judge, T. A. (2012). Organizational behavior (15th ed.) New Jersey, NY: Prentice Hall

Rotenberg, K. J., Macdonald, K. J., \& King, E. V. (2004). The relationship between loneliness and interpersonal trust during middle childhood. The Journal of Genetic Psychology. 165(3). 233249.

Santrock, J. W. (2005). Adolescence (10th ed.). New York, NY: Mc-GrawHill.

Santrock, J. W. (2011). Educational psychology (5th ed.). New York, NY: Mc-Graw-Hill.

Santrock, J. W. (2008). Life-span development (11 th ed.). New York, Ny: Mc-Graw-Hill.

Sigelman, C. K., Rider, E. A. (2006). Life-span human development (6th ed.). Belmont, CA. Thomson Higher Education.

Szcześniak. M., Colaço. M., \& Rondón. G. (2012). Development of interpersonal trust among children and adolescents. Polish Psychological Bulletin. 43(1). 50-58.

Tingkat perceraian di Indonesia meningkat. (2011). Diunduh dari m.detik.com/news/read/2011/08/04/124446/1696402/10/tingkat-perceraian-di-indonesiameningkat

Weiten, W., Lloyd, M. A., Dunn, D. S., \& Hammer, E. Y. (2009). Psychology applied to modern life: Adjustmeny in the $21^{\text {st }}$ century (9th ed.) Belmont, CA. Wadsworth Cengage Learning.

Zimmerman, J. Thayer, E. (2003). Adult children of divorce: How to overcome the legacy of your parents' breakup and enjoy love, trust, and intimacy. Oakland: CA. New Harbinger. 